\title{
Voluntary wheel running ameliorates symptoms of MK-801-induced schizophrenia in mice
}

\author{
TAE-WOON KIM ${ }^{1,2}$, HYUN-SIK KANG ${ }^{2}$, JOON-KI PARK $^{3}$, SAM-JUN LEE $^{4}$, \\ SANG-BIN BAEK ${ }^{5}$ and CHANG-JU KIM ${ }^{1}$
}

\begin{abstract}
${ }^{1}$ Department of Physiology, College of Medicine, Kyung Hee University, Seoul 130-701; ${ }^{2}$ Department of Exercise Physiology, School of Sport Science, Sungkyunkwan University, Suwon, Gyeonggi-do 440-746; ${ }^{3}$ Department of Exercise Physiology, Division of Exercise and Health Science, College of Arts and Physical Education, Incheon National University, Incheon 407-772; ${ }^{4}$ Department of Physical Education, College of Health, Social Welfare and Education, Tong Myong University, Busan 608-711; ${ }^{5}$ Department of Psychiatry, Gangneung Asan Hospital, Ulsan University, Gangneung, Gangwon 210-711, Republic of Korea
\end{abstract}

Received August 10, 2013; Accepted March 31, 2014

DOI: $10.3892 / \mathrm{mmr} .2014 .2644$

\begin{abstract}
Schizophrenia is a chronic and severe mental disorder characterized by the disintegration of cognitive thought processes and emotional responses. Despite the precise cause of schizophrenia remains unclear, it is hypothesized that a dysregulation of the $N$-methyl-D-aspartate (NMDA) receptor in the brain is a major contributing factor to its development. Brain-derived neurotrophic factor (BDNF) is a member of the neurotrophin family and is implicated in learning and memory processes. In the present study, we investigated in vivo the effects of voluntary wheel running on behavioral symptoms associated with NMDA receptor expression, using MK-801-induced schizophrenic mice. Abilify (aripiprazole), a drug used to treat human schizophrenia patients, was used as the positive control. For the assessment of behavioral symptoms affecting locomotion, social interaction and spatial working memory, the open-field, social interaction and Morris water maze tests were conducted. For investigating the biochemical parameters, NMDA receptor expression in the hippocampal CA2-3 regions and prefrontal cortex was detected by NMDA immunofluorescence and BDNF expression in the hippocampus was measured using western blot analysis. MK-801 injection for 14 days induced schizophrenia-like behavioral abnormalities with decreased expression of the NMDA receptor and BDNF in the brains of mice. The results indicated that free access to voluntary wheel running for 2 weeks alleviated schizophrenia-like behavioral
\end{abstract}

Correspondence to: Professor Chang-Ju Kim, Department of Physiology, College of Medicine, Kyung Hee University, 26 Kyungheedae-ro, Dongdaemun-gu, Seoul 130-701, Republic of Korea

E-mail: changju@khu.ac.kr

Key words: schizophrenia, N-methyl-D-aspartate receptor, brain-derived neurotrophic factor, voluntary wheel running, schizophrenia-like behaviors abnormalities and increased the expression of NMDA receptor and BDNF, comparable to the effects of aripiprazole treatment. In the present study, the results suggest that NMDA receptor hypofunctioning induced schizophrenia-like behaviors, and that voluntary wheel running was effective in reducing these symptoms by increasing NMDA receptor and BDNF expression, resulting in an improvement of disease related behavioral deficits.

\section{Introduction}

Schizophrenia is a serious psychiatric disorder that occurs in $\sim 0.5-1.0 \%$ of the worldwide population (1). The positive symptoms of schizophrenia include hallucinations, delusions, cognitive deficits and movement disorders, which are coupled with negative symptoms, such as the disruption of normal emotions and behaviors (2). Patients with schizophrenia suffer from severe deficits in mental processing and cognition, which are associated with dysfunctions in several key neural networks in the brain, including the frontal and temporal cortex, hippocampus and subcortical regions (3). In particular, abnormalities of the prefrontal cortex are implicated in working memory deficits $(4,5)$.

Dysregulation in physiological neurochemistry, including dopamine dysfunction, dopamine-glutamate imbalance and hypofunction of glutamate receptors, is considered as important in the pathogenesis of schizophrenia (6). The $N$-methyl-D-aspartate (NMDA) receptor is a glutamate receptor that is associated with a number of diverse functional properties within the sensory and motor systems (7), due to its role in regulating neuronal communication and synaptic functioning throughout the central nervous system (8). Alterations in NMDA receptor function are implicated in the pathophysiology of numerous psychiatric diseases, including schizophrenia, major depression, posttraumatic stress disorder and alcoholism $(9,10)$.

The NMDA receptor antagonists, ketamine and dizocilpine maleate (MK-801), dose-dependently impair spatial-delayed alternation performance. Furthermore, NMDA receptor antagonists and dopaminergic agonists have been used to 
induce schizophrenia in animal models (11). MK-801 is an NMDA receptor antagonist that has been used for inducing schizophrenia-like symptoms and behaviors in rodents (12). While dopaminergic agonists mimic only the positive symptoms of schizophrenia, MK-801-induced schizophrenic animals exhibit the positive and negative symptoms (11).

Numerous different neuroleptic drugs have been developed and proven to be partially effective in alleviating the behavioral symptoms of schizophrenia. Abilify (aripiprazole) is used to treat certain mental and mood disorders, including bipolar disorder and schizophrenia (13). This antipsychotic medication acts to improve mood swings, promote self-assurance, reduce anxiety and encourage participation in activities of everyday life (14).

Brain-derived neurotrophic factor (BDNF) is a member of the neurotrophin family that modulates the proliferation, differentiation and growth of hippocampal progenitor cells during the development of the vertebrate nervous system $(15,16)$. BDNF is implicated in learning and memory processes, as suppressing its expression leads to cognitive abnormalities and subsequent deficits (17). Furthermore, BDNF expression is selectively increased following activity-dependent learning and memory tasks (18).

Exercise has been recommended as a non-pharmacological strategy for treating those with neuropsychiatric diseases (19-22), however, little information is available regarding the effects of exercise on schizophrenia-related behavioral abnormalities. In the present study, we investigated the effects of voluntary wheel running on the behavioral symptoms associated with NMDA receptor expression in MK-801-induced schizophrenic mice.

\section{Materials and methods}

Animals and experimental design. Male C57BL/6 mice (6 weeks old, weighing $25 \pm 2 \mathrm{~g}$ ) were used in this study. The mice were individually housed in plastic cages at a controlled temperature $\left(23 \pm 2^{\circ} \mathrm{C}\right)$ and maintained under light-dark cycles consisting of $12 \mathrm{~h}$ of light $(08: 00 \mathrm{~h}$ to $20: 00 \mathrm{~h})$ and $12 \mathrm{~h}$ of dark and were provided with food and water ad libitum. Experimental procedures were performed in accordance with the animal care guidelines of the National Institutes of Health (NIH) and the Korean Academy of Medical Sciences (Seoul, Korea). This study was approved by the Institutional Animal Care and Use Committee of Kyung Hee University (Seoul, Korea). The mice were divided into four groups $(n=10$ in each group): the control group, the MK-801 injection group, the MK-801 injection and wheel running group and the MK-801 injection and aripiprazole-treated group. Aripiprazole was purchased from the Korea Otsuka Pharmaceutical Co., Ltd. (Seoul, Korea).

The mice in the MK-801 injection and voluntary wheel running group were housed individually with free access to an appropriately sized running wheel for 2 weeks. A digital counter was used to measure the total number of revolutions of the running wheel. Data were downloaded every morning and

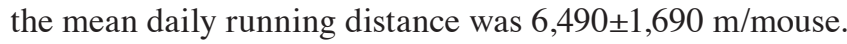

Preparation of MK-801-induced schizophrenia model in mice. MK-801 is a non-competitive NMDA receptor antagonist and was purchased from the Sigma Chemical Co.
(St. Louis, MO, USA). MK-801 was prepared as a stock solution (1 mg/ml, dissolved in saline) and $0.6 \mathrm{mg} / \mathrm{kg}$ of it was intraperitoneally (i.p.) injected once a day for 2 weeks as previously described (12).

Open field test. To determine locomotion activity, an open field test was conducted two weeks following the start of the study, as previously described (23). An open field test was performed in an open arena (length $85 \mathrm{~cm} x$ width $75 \mathrm{~cm} \mathrm{x}$ height $30 \mathrm{~cm}$ ). After allowing an initial $1 \mathrm{~min}$ for adaptation to the cubic area, the total distance traveled during an additional 5 min was recorded as the locomotion activity, using an automatic video tracking system (Smart version 2.5; Panlab, S.L.U., Barcelona, Spain).

Social interaction test. The social interaction test was performed two weeks after the study began, as previously described (24). Two weight-matched mice, drawn from different cages, were used for this test. The normal mouse was used as the dummy partner and the index mouse was marked with an oil pen. The mice were then placed in the center of an open arena (length $85 \mathrm{~cm} \mathrm{x}$ width $75 \mathrm{~cm}$ x height $30 \mathrm{~cm}$ ). The animals were closely observed and the interactions exhibited by the index mouse were recorded over a period of $7 \mathrm{~min}$. The social behaviors (genital investigation, sniffing, following, grooming) demonstrated by the index mouse were visually assessed throughout the duration of the test period.

Morris water maze test. Spatial working memory was evaluated using the Morris water maze task, as previously described (25). This task requires mice to learn the spatial location of a hidden platform in a white circular pool $(140 \mathrm{~cm}$ in diameter and $45 \mathrm{~cm}$ in height) filled with water $\left(25 \pm 1^{\circ} \mathrm{C}\right)$. The hidden platform (15 cm in diameter and $35 \mathrm{~cm}$ in height) was placed $2 \mathrm{~cm}$ below the surface of water in the middle of the north quadrant and was camouflaged by virtue of being transparent against a white background. Distal visual cues were placed on the walls surrounding the pool. The position of the cues remained unchanged throughout the task. One day prior to the start of training, the mice were habituated to swimming for $60 \mathrm{sec}$ in the pool without a platform. The test consisted of three acquisition phases and two probe trials. In the acquisition phase, all mice were trained twice a day for three consecutive days. When finding the platform, the mice were allowed to remain for $30 \mathrm{sec}$. If mice did not find the platform within $60 \mathrm{sec}$, they were guided by hand to the platform. Mice were given $60 \mathrm{sec}$ of the probe test and then the platform was removed from the pool. Total occupancy time in the quadrant that had the platform was recorded automatically by a video tracking system (Panlab, S.L.U.).

Tissue preparation. The mice were sacrificed 15 days following the start of the study. At the beginning of the sacrificial procedure, the animals were weighed and overdosed with Zoletil $50^{\circledR}(10 \mathrm{mg} / \mathrm{kg}$, i.p.; Vibac Laboratories, Carros, France). After a complete lack of response was observed, the mice were transcardially perfused with $50 \mathrm{mM}$ of phosphate-buffered saline (PBS) and then with 4\% of paraformaldehyde in a $100 \mathrm{mM}$ phosphate buffer (PB) at $\mathrm{pH}$ 7.4. The brains were dissected, postfixed in the same fixative overnight and transferred into a 


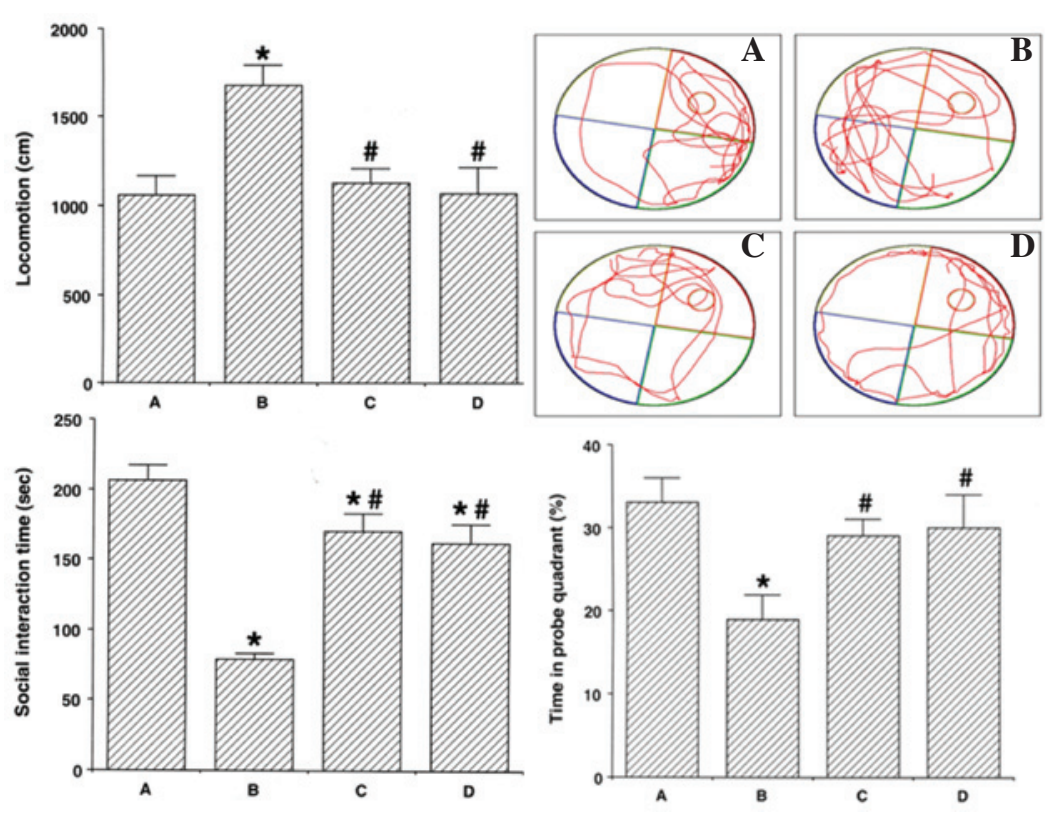

Figure 1. Effects of wheel running on locomotion distance, social interaction time and spatial working memory. Left upper: Locomotion distance in the open field test. Left lower: Time of social interaction in the social interaction test. Right: Morris water maze test. (A) Control group; (B) MK-801 injection group; (C) MK-801 injection and wheel running group and (D) MK-801 injection and aripiprazole-treated group. Data are expressed as the mean \pm SEM. ${ }^{*} \mathrm{P}<0.05$ compared with the control group; ${ }^{\#} \mathrm{P}<0.05$ compared with the MK-801 injection group. MK-801, dizocilpine maleate; SEM, standard error of the mean.

$30 \%$ sucrose solution for cryoprotection. Brains were rapidly frozen in a deep freezer at $-80^{\circ} \mathrm{C}$ and serial coronal sections of $40 \mathrm{~mm}$ thickness were conducted using a freezing microtome (Leica, Nussloch, Germany).

Immunofluorescence for NMDA receptor assays. To visualize NMDA receptor expression, immunofluorescence for NMDA receptor was performed, as previously described (25). Brain sections were selected and incubated overnight with goat anti-NMDA receptor antibody. After washing, the sections were incubated for $2 \mathrm{~h}$ with fluorescent isothiocyanate (FITC)-conjugated goat anti-rabbit secondary antibody (Jackson ImmunoResearch Laboratories, West Grove, PA, USA). The sections were then mounted on gelatin-coated glass slides and the coverslips were mounted using a fluorescent mounting medium (DakoCytomation, Carpinteria, CA, USA). The slides of the fluorescent images were captured using confocal laser-scanning microscopy with LSM 510 META (Carl Zeiss, Oberkochen, Germany). Negative controls were performed by omitting the primary antibody and therefore did not exhibit any signals.

Western blotting for BDNF expression. BDNF expression was determined using western blot analysis, as previously described (26). Collected hippocampal tissues were immediately frozen at $-70^{\circ} \mathrm{C}$. The hippocampal tissues were homogenized on ice and lysed in a lysis buffer containing $50 \mathrm{mM}$ Tris- $\mathrm{HCl}$ (pH 7.5), $150 \mathrm{mM} \mathrm{NaCl}, 0.5 \%$ deoxycholic acid, $1 \%$ Nonidet P-40, $0.1 \%$ SDS, $1 \mathrm{mM} \mathrm{PMSF}$ and $100 \mathrm{mg} / \mathrm{ml}$ leupeptin. Protein content was measured using a Bio-Rad colorimetric protein assay kit (Bio-Rad, Hercules, CA, USA), then $30 \mu \mathrm{g}$ of protein was separated on SDS-polyacrylamide gels and transferred onto a nitrocellulose membrane, which was incubated with mouse $\beta$-actin antibody (1:3,000; Santa
Cruz Biotechnology, Inc., Santa Cruz, CA, USA) and rabbit BDNF antibody (1:1,000; Santa Cruz Biotechnology, Inc.). Horseradish peroxidase-conjugated anti-rabbit antibody for BDNF was used as the secondary antibody. The experiment was performed under normal lab conditions and at room temperature except for the transferred membrane, which was performed at $4^{\circ} \mathrm{C}$ with a cold pack and prechilled buffer. Band detection was performed using an enhanced chemiluminescence (ECL) detection kit (Santa Cruz Biotechnology, Inc.).

Data analysis. The number of NMDA receptor-positive cells in the hippocampal CA2-3 regions and prefrontal cortex were counted hemilaterally under a light microscope (Olympus, Tokyo, Japan) and they were expressed as the number of cells $/ \mathrm{mm}^{2}$ in the selected areas. To confirm the expression of BDNF, detected bands were calculated densitometrically using Molecular Analyst ${ }^{\mathrm{TM}}$, version 1.4.1 (Bio-Rad). Statistical analysis was performed using a one-way analysis of variance (ANOVA) followed by Duncan's post-hoc test. Results are expressed as the mean \pm standard error of the mean (SEM). $\mathrm{P}<0.05$ was considered to indicate a statistically significant difference.

\section{Results}

Effect of wheel running on the locomotion distance. The locomotion distance in the open field test was $1057.58 \pm 106.97 \mathrm{~cm}$ in the control group, $1677.63 \pm 116.29 \mathrm{~cm}$ in the MK-801 injection group, $1125.80 \pm 83.63 \mathrm{~cm}$ in the MK-801 injection and wheel running group and $1065.78 \pm 150.01 \mathrm{~cm}$ in the MK-801 injection and aripiprazole-treated group (Fig. 1, upper left). Locomotion distance in MK-801-injected mice was significantly higher compared with that in normal mice $(\mathrm{P}<0.05)$, however, wheel running and aripiprazole treatment decreased locomotion distance in the MK-801-injected mice $(\mathrm{P}<0.05)$. 

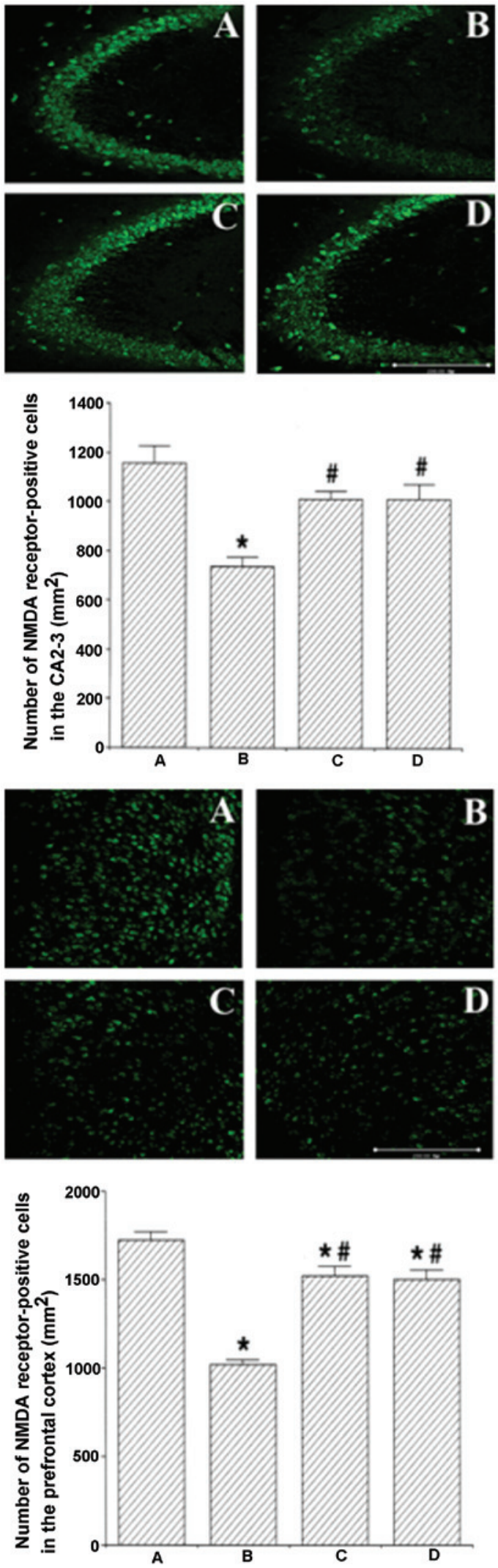

Figure 2. Effects of wheel running on the number of NMDA-receptorpositive cells in hippocampal CA2-3 regions and the prefrontal cortex Upper: Number of NMDA receptor-positive cells in hippocampal CA2-3 regions. Lower: Number of NMDA receptor-positive cells in the prefrontal cortex. Scale bars represent $200 \mu \mathrm{m}$. (A) Control group; (B) MK-801 injection group; (C) MK-801 injection and wheel running group and (D) MK-801 injection and aripiprazole-treated group. Data are expressed as the mean \pm SEM. ${ }^{*} \mathrm{P}<0.05$ compared with the control group; ${ }^{*} \mathrm{P}<0.05$ compared with the MK-801 injection group. NMDA, N-methyl-D-aspartate; MK-801, dizocilpine maleate; SEM, standard error of the mean.
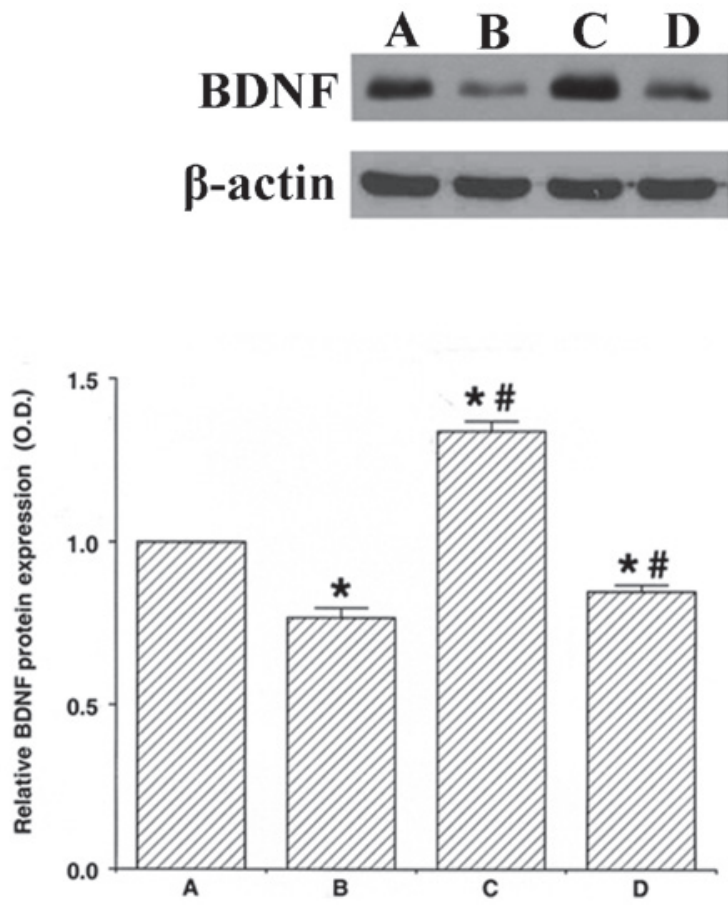

Figure 3. Effect of wheel running on BDNF expression in the hippocampus. (A) Control group; (B) MK-801 injection group; (C) MK-801 injection and wheel running group and (D) MK-801 injection and aripiprazole-treated group. Data are expressed as the mean \pm SEM. ${ }^{*} \mathrm{P}<0.05$ compared with the control group; ${ }^{\text {}} \mathrm{P}<0.05$ compared with the MK-801 injection group. BDNF, brain-derived neurotrophic factor; MK-801, dizocilpine maleate; SEM, standard error of the mean.

Effect of wheel running on social interaction time. Time spent socially interacting was $206.60 \pm 10.99 \mathrm{sec}$ in the control group, $78.60 \pm 4.01 \mathrm{sec}$ in the MK-801 injection group, $170.20 \pm 13.13 \mathrm{sec}$ in the MK-801 injection and wheel running group and $162.25 \pm 12.99 \mathrm{sec}$ in the MK-801 injection and aripiprazole-treated group (Fig. 1, lower left). The time that MK-801-injected mice spent socially interacting was lower compared with that spent by normal mice $(\mathrm{P}<0.05)$, but the wheel running and aripiprazole treatment increased the time that MK-801-injected mice spent socially interacting $(\mathrm{P}<0.05)$.

Effect of wheel running on spatial working memory. The percentage of time spent in the probe quadrant of the Morris water maze test was $32.96 \pm 3.00 \%$ in the control group, $19.12 \pm 3.41 \%$ in the MK-801 injection group, $28.94 \pm 1.66 \%$ in the MK-801 injection and wheel running group and $30.03 \pm 4.11 \%$ in the MK-801 injection and aripiprazole-treated group (Fig. 1, right). The percentage of time that the MK-801-injected mice spent in the probe quadrant was lower than that in normal mice $(\mathrm{P}<0.05)$. Wheel running and aripiprazole treatment increased the percentage of time MK-801-injected mice spent in the probe quadrant $(\mathrm{P}<0.05)$.

Effects of wheel running on NMDA receptor expression in hippocampal CA2-3 regions and the prefrontal cortex. The number of NMDA receptor-positive cells in hippocampal CA2-3 regions was $1154.06 \pm 73.09 / \mathrm{mm}^{2}$ in the control group, $739.03 \pm 34.51 / \mathrm{mm}^{2}$ in the MK-801 injection group, $1007.89 \pm 35.20 / \mathrm{mm}^{2}$ in the MK-801 injection and wheel running group and $1012.28 \pm 59.32 / \mathrm{mm}^{2}$ in the MK-801 
injection and aripiprazole-treated group (Fig. 2, left). The number of NMDA receptor-positive cells in the prefrontal cortex was $1724.10 \pm 47.50 / \mathrm{mm}^{2}$ in the control group, $1022.50 \pm 28.03 / \mathrm{mm}^{2}$ in the MK-801 injection group, $1517.81 \pm 53.54 / \mathrm{mm}^{2}$ in the MK-801 injection and wheel running group and $1498.21 \pm 53.54 / \mathrm{mm}^{2}$ in the MK-801 injection and aripiprazole-treated group (Fig. 2, right). The number of NMDA receptor-positive cells in hippocampal CA2-3 regions and the prefrontal cortex of the MK-801-injected mice was lower than that in normal mice $(\mathrm{P}<0.05)$. Wheel running and aripiprazole treatment increased this number in MK-801-injected mice $(\mathrm{P}<0.05)$.

Effect of wheel running on BDNF expression in the hippocampus. The level of BDNF expression in the hippocampus of the control group was set as 1.00. The level of BDNF expression was $0.77 \pm 0.03$ in the MK-801 injection group, $1.34 \pm 0.03$ in the MK-801 injection and wheel running group and $0.85 \pm 0.02$ in the MK-801 injection and aripiprazole-treated group (Fig. 3). The expression of BDNF in the MK-801-injected mice was lower than that in normal mice $(\mathrm{P}<0.05)$. Wheel running and aripiprazole treatment increased the expression of BDNF in the MK-801-injected mice $(\mathrm{P}<0.05)$.

\section{Discussion}

The importance of NMDA receptors in the pathogenesis of schizophrenia is well documented. A postmortem study by Harrison et al (27) demonstrated that NMDA receptor subunit expression was reduced in various brain regions of schizophrenic patients, particularly in the hippocampus. NMDA receptor hypomorphic mice exhibit alterations in sensorimotor gating and typical conspecific interactions, reminiscent of behavioral disturbances associated with schizophrenia (28). NMDA receptor antagonists cause locomotor hyperactivity similar to that observed in schizophrenia (29). Impaired working memory in schizophrenia is associated with a decline in dorsolateral prefrontal cortex activity (30). Furthermore, reduced NMDA receptor functioning has been correlated with an increase in locomotor activity, and non-dopaminergic blocking agents, such as olanzapine, reduce hyperactivity in NMDA receptor-deficient mice (31). NMDA receptor obligatory subunit 1 deletion knockout mice are impaired in prepotent inhibition of the auditory startle reflex, as well as in object-based short-term memory (32). In the present study, repeated injections of the NMDA receptor antagonist MK-801 reduced the expression of NMDA receptors in hippocampal CA2-3 regions and the prefrontal cortex, indicating the presence of schizophrenia-like biochemical alterations in the brain. In the open field test, mice in the MK-801 injection group demonstrated a greater increase in locomotion distance compared with mice in the control group. Decreased social interaction time was also observed in the MK-801-injected mice. These results suggest that reducing NMDA receptor produces schizophrenia-like behavioral abnormalities in mice.

A reduction in short-term and spatial working memory is a characteristic feature of the normal aging process, and is accompanied with suppression of BDNF expression in the hippocampus (33). The results of this study are consistent with those of previous studies, which demonstrated that enhanced
BDNF expression in the hippocampus improves short-term and long-term memories $(34,35)$. Of note, BDNF expression in the hippocampus is suppressed by traumatic brain injury, suggesting that BDNF exerts a neuroprotective effect (36). The NMDA receptor antagonist MK-801 also suppresses hippocampal expression of BDNF (37). Decreased BDNF expression has been identified in several mental disorders, including schizophrenia and depression $(26,38)$. Furthermore, induction of intracerebral hemorrhage has been demonstrated to suppress BDNF expression in the hippocampus, with the impairment in spatial learning memory occurring as a result (39). In the present study, repeated injections of the NMDA receptor antagonist MK-801 suppressed BDNF expression in the hippocampus. Impairment in spatial working memory was also observed in the MK-801-injected mice. These results suggest that MK-801 injections deteriorated spatial working memory by depressing BDNF expression in the hippocampus.

The benefits of exercise on brain functioning are well documented $(20,22,25,40)$. Beebe et al (19) reported that experimental participants in a 16-week walking program for outpatients diagnosed with schizophrenia had greater aerobic fitness, lower body mass indexes and fewer psychiatric symptoms, than the controls at the conclusion of the program. In the present study, mice with free access to wheel running demonstrated decreased locomotor activity, enhanced social interaction time and improved spatial working memory, which was comparable to the effects of aripiprazole treatment.

The glutamate receptor, NMDA, is involved in activity-dependent synaptic plasticity, including long-term potentiation (41). It was identified that exercise is a necessary step for initiating activity of the NMDA receptor in the hippocampus (42) and that exercise-enhanced NMDA receptor expression promotes postnatal motor-unit maturation in a spinal muscular atrophy mouse model (43). Treadmill exercise increases NMDA receptor immunoreactivity and protein level in the hippocampus (44). Nishijima et al (45) suggested that exercise-induced increase in hippocampal cerebral blood flow is regulated by hippocampal neuronal activity, mediated mainly through the NMDA receptor. In the present study, mice that participated in voluntary wheel running demonstrated enhanced NMDA receptor expression in the hippocampus, comparable to the effects of aripiprazole treatment. These results suggest that exercise alleviates the symptoms of schizophrenia by enhancing NMDA receptor expression in the hippocampus.

The enhancement effect of physical exercise on hippocampal BDNF expression has been consistently reported in previous studies $(36,46,47)$. Enhanced BDNF expression in the hippocampus via exercise inhibits age-induced deterioration of short-term and spatial working memories (33). Exercise-induced BDNF expression also alleviates spatial working memory impairment in attention deficit/hyperactivity disorder (ADHD) rats (21). Voluntary wheel running is more effective in the upregulation of hippocampal BDNF levels in rats with brain ischemia, as compared with forced treadmill running (48). In the present study, voluntary wheel running enhanced BDNF expression in the hippocampus, comparable to the effects of aripiprazole treatment. These results suggest that exercise alleviates spatial working memory impairment by enhancing BDNF expression in schizophrenic mice. 
Based on the present findings, it was concluded that NMDA receptor hypofunctioning induces schizophrenia-like behaviors in mice. Physical exercise increases NMDA receptor expression by enhancing BDNF expression, resulting in improvement of schizophrenia-like behaviors. The present study suggests that voluntary regular exercise may facilitate in alleviating the symptoms of schizophrenia in human patients.

\section{Acknowledgements}

This study was supported by the Research Fund from Kyung Hee University at the year of 2010 (KHU 20100848).

\section{References}

1. Freedman R: Schizophrenia. N Engl J Med 349: 1738-1749, 2003.

2. Ross CA, Margolis RL, Reading SA, Pletnikov M and Coyle JT: Neurobiology of schizophrenia. Neuron 52: 139-153, 2006.

3. Kuperberg G and Heckers S: Schizophrenia and cognitive function. Curr Opin Neurobiol 10: 205-210, 2000.

4. Manoach DS: Prefrontal cortex dysfunction during working memory performance in schizophrenia: reconciling discrepant findings. Schizophr Res 60: 285-298, 2003.

5. Meyer-Lindenberg A, Miletich RS, Kohn PD, Esposito G, Carson RE, Quarantelli M, Weinberger DR and Berman KF: Reduced prefrontal activity predicts exaggerated striatal dopaminergic function in schizophrenia. Nat Neurosci 5: 267-271, 2002.

6. Carlsson A, Waters N and Carlsson ML: Neurotransmitter interactions in schizophrenia - therapeutic implications. Biol Psychiatry 46: 1388-1395, 1999.

7. Daw NW, Stein PS and Fox K: The role of NMDA receptors in information processing. Annu Rev Neurosci 16: 207-222, 1993.

8. Köhr G: NMDA receptor function: subunit composition versus spatial distribution. Cell Tissue Res 326: 439-446, 2006.

9. Coyle JT: Glutamate and schizophrenia: beyond the dopamine hypothesis. Cell Mol Neurobiol 26: 365-384, 2006.

10. Heresco-Levy U and Javitt DC: The role of N-methyl-D-aspartate (NMDA) receptor-mediated neurotransmission in the pathophysiology and therapeutics of psychiatric syndromes. Eur Neuropsychopharmacol 8: 141-152, 1998.

11. Rung JP, Carlsson A, Rydén Markinhuhta K and Carlsson ML: (+)-MK-801 induced social withdrawalin rats; a model for negative symptoms of schizophrenia. Prog Neuropsychopharmacol Biol Psychiatry 29: 827-832, 2005.

12. Yu J, Qi D, Xing M, Li R, Jiang K, Peng Y and Cui D: MK-801 induces schizophrenic behaviors through downregulating Wnt signaling pathways in male mice. Brain Res 1385: 281-292, 2011.

13. Youngstrom E, Zhao J, Mankoski R, Forbes RA, Marcus RM, Carson W, McQuade R and Findling RL: Clinical significance of treatment effects with aripiprazole versus placebo in a study of manic or mixed episodes associated with pediatric bipolar I disorder. J Child Adolesc Psychopharmacol 23: 72-79, 2013.

14. Lerond J, Lothe A, Ryvlin P, Bouvard S, d'Amato T, Ciumas C, Daléry J, Poulet E and Saoud M: Effects of aripiprazole, risperidone, and olanzapine on 5-HT1A receptors in patients with schizophrenia. J Clin Psychopharmacol 33: 84-89, 2013.

15. Huang EJ and Reichardt LF: Neurotrophins: roles in neuronal development and function. Annu Rev Neurosci 24: 677-736, 2001.

16. Lee E and Son H: Adult hippocampal neurogenesis and related neurotrophic factors. BMB Rep 42: 239-244, 2009.

17. Gomez-Pinilla F and Vaynman S: A "deficient environment" in prenatal life may compromise systems important for cognitive function by affecting BDNF in the hippocampus. Exp Neurol 192: 235-243, 2005

18. Zimmerberg B, Foote HE and Van Kempen TA: Olfactory association learning and brain-derived neurotrophic factor in an animal model of early deprivation. Dev Psychobiol 51: 333-344, 2009.

19. Beebe LH, Tian L, Morris N, Goodwin A, Allen SS and Kuldau J: Effects of exercise on mental and physical health parameters of persons with schizophrenia. Issues Ment Health Nurs 26: 661-676, 2005.
20. Cho HS, Shin MS, Song W, Jun TW, Lim BV, Kim YP and Kim CJ: Treadmill exercise alleviates short-term memory impairment in 6-hydroxydopamine-induced Parkinson's rats. J Exerc Rehabil 9: 354-361, 2013.

21. Kim H, Heo HI, Kim DH, Ko IG, Lee SS, Kim SE, Kim BK, Kim TW, Ji ES, Kim JD, et al: Treadmill exercise and methylphenidate ameliorate symptoms of attention deficit/hyperactivity disorder through enhancing dopamine synthesis and brain-derived neurotrophic factor expression in spontaneous hypertensive rats. Neurosci Lett 504: 35-39, 2011.

22. Lang R, Koegel LK, Ashbaugh K, Regester A, Ence W and Smith W: Physical exercise and individuals with autism spectrum disorders: A systematic review. Res Autism Spectr Disord 4: 565-576, 2010.

23. Durand M, Berton O, Aguerre S, Edno L, Combourieu I, Mormède $\mathrm{P}$ and Chaouloff $\mathrm{F}$ : Effects of repeated fluoxetine on anxiety-related behaviours, central serotonergic systems, and the corticotropic ax is in SHR and WKY rats. Neuropharmacolog y 38 : 893-907, 1999.

24. Dandekar MP, Singru PS, Kokare DM, Lechan RM, Thim L, Clausen JT and Subhedar NK: Importance of cocaine- and amphetamine-regulated transcript peptide in the central nucleus of amygdala in anxiogenic responses induced by ethanol withdrawal. Neuropsychopharmacology 33: 1127-1136, 2008.

25. Shin MS, Ko IG, Kim SE, Kim BK, Kim TS, Lee SH, Hwang DS, Kim CJ, Park JK and Lim BV: Treadmill exercise ameliorates symptoms of methimazole-induced hypothyroidism through enhancing neurogenesis and suppressing apoptosis in the hippocampus of rat pups. Int J Dev Neurosci 31: 214-223, 2013.

26. Kim JE, Ji ES, Seo JH, Lee MH, Cho S, Park YK, Seo TB and Kim CJ: Alcohol exposure induces depression-like behavior by decreasing hippocampal neuronal proliferation through inhibition of the BDNF-ERK pathway in gerbils. Anim Cells Syst 16: 190-197, 2012.

27. Harrison PJ, Law AJ and Eastwood SL: Glutamate receptors and transporters in the hippocampus in schizophrenia. Ann NY Acad Sci 1003: 94-101, 2003.

28. Duncan GE, Moy SS, Perez A, Eddy DM, Zinzow WM, Lieberman JA, Snouwaert JN and Koller BH: Deficits in sensorimotor gating and tests of social behavior in a genetic model of reduced NMDA receptor function. Behav Brain Res 153: 507-519, 2004.

29. Leriche L, Schwartz JC and Sokoloff P: The dopamine D3 receptor mediates locomotor hyperactivity induced by NMDA receptor blockade. Neuropharmacology 45: 174-181, 2003.

30. Jansma JM, Ramsey NF, van der Wee NJ and Kahn RS: Working memory capacity in schizophrenia: a parametric fMRI study. Schizophr Res 68: 159-171, 2004.

31. Duncan GE, Moy SS, Lieberman JA and Koller BH: Typical and atypical antipsychotic drug effects on locomotor hyperactivity and deficits in sensorimotor gating in a genetic model of NMDA receptor hypofunction. Pharmacol Biochem Behav 85: 481-491, 2006.

32. Rompala GR, Zsiros V, Zhang S, Kolata SM and Nakazawa K: Contribution of NMDA receptor hypofunction in prefrontal and cortical excitatory neurons to schizophrenia-like phenotypes. PLoS One 8: e61278, 2013.

33. Kim SE, Ko IG, Kim BK, Shin MS, Cho S, Kim CJ, Kim SH, Baek SS, Lee EK and Jee YS: Treadmill exercise prevents aging-induced failure of memory through an increase in neurogenesis and suppression of apoptosis in rat hippocampus. Exp Gerontol 45: 357-365, 2010.

34. Sairanen M, Lucas G, Ernfors P, Castrén M and Castrén E: Brain-derived neurotrophic factor and antidepressant drugs have different but coordinated effects on neuronal turnover, proliferation, and survival in the adult dentate gyrus. J Neurosci 25: 1089-1094, 2005.

35. Suzuki A, Fukushima H, Mukawa T, Toyoda H, Wu LJ, Zhao MG, $\mathrm{Xu} \mathrm{H}$, Shang Y, Endoh K, Iwamoto T, et al: Upregulation of CREBmediated transcription enhances both short- and long-term memory. J Neurosci 31: 8786-8802, 2011.

36. Baek SS, Jun TW, Kim KJ, Shin MS, Kang SY and Kim CJ: Effects of postnatal treadmill exercise on apoptotic neuronal cell death and cell proliferation of maternal-separated rat pups. Brain Dev 34: 45-56, 2012.

37. Fumagalli F, Molteni R, Roceri M, Bedogni F, Santero R, Fossati C, Gennarelli M, Racagni G and Riva MA: Effect of antipsychotic drugs on brain-derived neurotrophic factor expression under reduced $\mathrm{N}$-methyl-D-aspartate receptor activity. J Neurosci Res 72: 622-628, 2003. 
38. Knable MB, Barci BM, Webster MJ, Meador-Woodruff J and Torrey EF: Molecular abnormalities of the hippocampus in severe psychiatric illness: postmortem findings from the Stanley Neuropathology Consortium. Mol Psychiatry 9: 609-620, 2004

39. Hwang L, Choi IY, Kim SE, Ko IG, Shin MS, Kim CJ, Kim SH, Jin JJ, Chung JY and Yi JW: Dexmedetomidine ameliorates intracerebral hemorrhage-induced memory impairment by inhibiting apoptosis and enhancing brain-derived neurotrophic factor expression in the rat hippocampus. Int J Mol Med 31: 1047-56, 2013

40. Kim SE, Ko IG, Park CY, Shin MS, Kim CJ and Jee YS: Treadmill and wheel exercise alleviate lipopolysaccharide-induced short-term memory impairment by enhancing neuronal maturation in rats. Mol Med Rep 7: 31-36, 2013.

41. Vasuta C, Caunt C, James R, Samadi S, Schibuk E, Kannangara T, Titterness AK and Christie BR: Effects of exercise on NMDA receptor subunit contributions to bidirectional synaptic plasticity in the mouse dentate gyrus. Hippocampus 17: 1201-1208, 2007.

42. Dietrich MO, Mantese CE, Porciuncula LO, Ghisleni G, Vinade L, Souza DO and Portela LV: Exercise affects glutamate receptors in postsynaptic densities from cortical mice brain. Brain Res 1065: 20-25, 2005.
43. Biondi O, Grondard C, Lécolle S, Deforges S, Pariset C, Lopes P, Cifuentes-Diaz C, Li H, della Gaspera B, Chanoine C and Charbonnier F: Exercise-induced activation of NMDA receptor promotes motor unit development and survival in a type 2 spinal muscular atrophy model mouse. J Neurosci 28: 953-962, 2008.

44. Choi JH, Yoo KY, Lee CH, Yi SS, Yoo DY, Seong JK, Yoon YS, Hwang IK and Won MH: Effects of treadmill exercise combined with MK 801 treatment on neuroblast differentiation in the dentate gyrus in rats. Cell Mol Neurobiol 31: 285-292, 2011.

45. Nishijima T, Okamoto M, Matsui T, Kita I and Soya H: Hippocampal functional hyperemia mediated by NMDA receptor/NO signaling in rats during mild exercise. J Appl Physiol (1985) 112: 197-203, 2012.

46. Duman CH, Schlesinger L, Russell DS and Duman RS: Voluntary exercise produces antidepressant and anxiolytic behavioral effects in mice. Brain Res 1199: 148-158, 2008.

47. Huang AM, Jen CJ, Chen HF, Yu L, Kuo YM and Chen HI: Compulsive exercise acutely upregulates rat hippocampal brain-derived neurotrophic factor. J Neural Transm 113: 803-811, 2006.

48. Ke Z, Yip SP,Li L,Zheng XX and Tong KY: The effects of voluntary, involuntary, and forced exercises on brain-derived neurotrophic factor and motor function recovery: a rat brain ischemia model. PLoS One 6: e16643, 2011. 